\title{
ECO-TRADITIONAL COURTYARD HOUSES IN UAE: A CASE STUDY OF THE SHARJAH MUSEUMS
}

\author{
IMAN IBRAHIM \\ Architecture and Interior Design, University of Sharjah, UAE
}

\begin{abstract}
A courtyard is an architectural design element traditionally and commonly integrated in UAE vernacular architecture for its environmental and social potential that reflects the sustainable design bases in traditional architecture. This research provides a qualitative study on the usefulness of courtyards as passive energy saving systems in the UAE. This includes my investigation into traditional old houses in Sharjah, to compare their courtyards' traditional use with the recent use of these courtyards after renovations and the changes in functions of some houses that currently are used as art exhibitions or museums. The research purpose is to focus on the application of courtyards in the context of the Heart of Sharjah public buildings, that reused the internal courtyards spaces for various community activities to create a socially active hub, to represent the cultural and traditional aspects for the Emirates community and its recognizable character, that express the community's cultural needs and extend the communication roots by introducing some historical background to new generations. The aim is also to raise awareness of the potential environmental aspects of courtyards in the hot dry climate of the UAE, with respect to the vision of sustainable architecture that reflects the natural context, including the climate conditions, the human context, and traditional cultural values. In addition, the research investigates the strength of the relation between the well-designed courtyard and its occupants' social behavior: the social aspects of sustainability traditionally and recently as well. The research study is qualitative and based on interviews, surveys and technical measurements that targeted public visitors to the selected buildings as a case study. The results from the analytical part of the research, including a list of recommendations to be applied to the traditional houses in Sharjah for their renovation and preparation for public use in terms of the cultural building principles that match the traditional and environmental aspects of sustainability.
\end{abstract}

Keywords: traditional architecture, courtyard house, Sharjah heart, sustainability.

\section{INTRODUCTION}

The research methodology involves qualitative analysis for the selected old traditional houses in Sharjah that integrates theoretical models with empirical ones that test the appropriateness of the research hypotheses of sustainability potentials in traditional architecture in the UAE, and Sharjah Emirate in particular.

The growing concern for traditional architecture and historical buildings is part of the global concern to preserve the heritage. Previous research highlighted the importance of traditional architecture, and its connection to the wider view for sustainability. That was clear in previous definitions for traditional architecture which as Kennedy stated is "An architecture style that develops from the particular climate and social conditions of a place" [1]. Another definition was given by Rashed Bukhash who considered that traditional architecture contains many values of peoples' lifestyles in an area and translates their needs in a unique character [2]. The research in this paper considered all previous definitions of traditional architecture, and so claims that traditional architecture is related to sustainability, as both consist of social, environmental and economic potentials

"Yet, to the Arab especially, the courtyard is more than just an architecture device for obtaining privacy and protection. It is, like the dome, part of a microcosm that parallels the order of the universe itself." Hassan Fathy inspired many architects by these words giving the courtyard a special deep concept to the Arab world architecture [3]. 
The courtyard house was a common architectural expression in many civilizations, and continues to be in the Arab countries as part of their vernacular architecture. The research claims that the courtyard is a unique dominant element that exists in most of vernacular architecture types in the Arab world's traditional architecture. The hot, arid climate of the Middle East was one of the driving forces in adopting courtyards into the architectural vernacular. The courtyard allowed builders to temper the climate indoors by affecting the wind, humidity, and sunlight. Another important driving force for the prominence of courtyards in the Middle East is the social aspects attached to an open central space.

\section{THE COURTYARD CONCEPT AND SUSTAINABILITY}

The courtyard house plan type existed throughout the world centuries ago. It became a prototype in urban design strategies for the hot arid zones. In addition to a functional, important role for climate control in the courtyard house, a traditional cultural relevance of importance in Arab countries, this type of architecture proved to have efficient purposes.

Courtyards as a prototype plan have two basic components: to respect and to accommodate the climate as the environmental aspect of sustainability, since the major function for the courtyard is to control the environment and to maintain suitable weather for the humans, as well as to create an inner environment, that provides privacy and solitude environment. The second aspect is the social one that includes Islamic and cultural fundamentals that have to be considered, and to reflect the social aspect of sustainability.

The research demonstrates that the courtyards' design is an essential part of the vernacular traditional architecture. It serves the principles of sustainability as a multi-dimensional concept that includes economic, social and environmental dimensions.

\subsection{Courtyard climate study}

The demands of a hot climate led to a number of design characteristics. A courtyard is a wellrecognized one that has been used for many centuries in houses, schools, mosques and government buildings.

The climate of Arab countries, and the UAE generally is very hot and sunny. The hottest months are July and August, when average maximum temperatures reach above $50^{\circ} \mathrm{C}$ $\left(122.0^{\circ} \mathrm{F}\right)$ on the coastal plain, a result of increased altitude. Average minimum temperatures

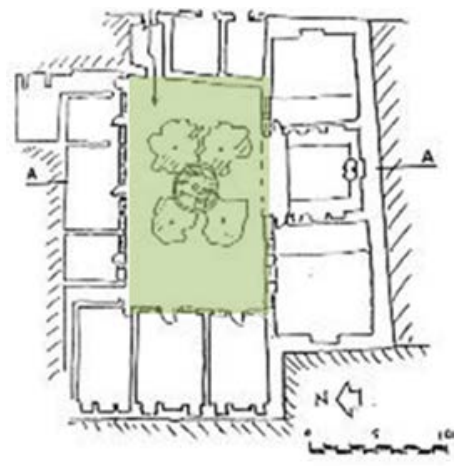

(a)

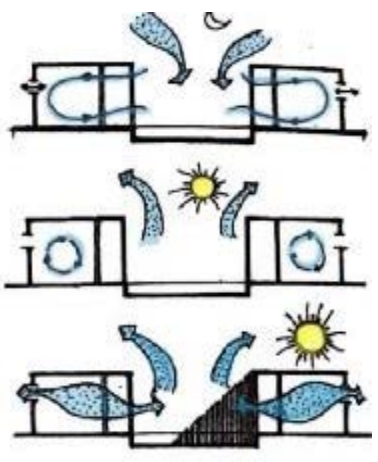

(b)

Figure 1: A sketch of a courtyard house. (a) Plan drawing; (b) Air circulation between courtyard and adjoining rooms at night, midday and afternoon [5]. 


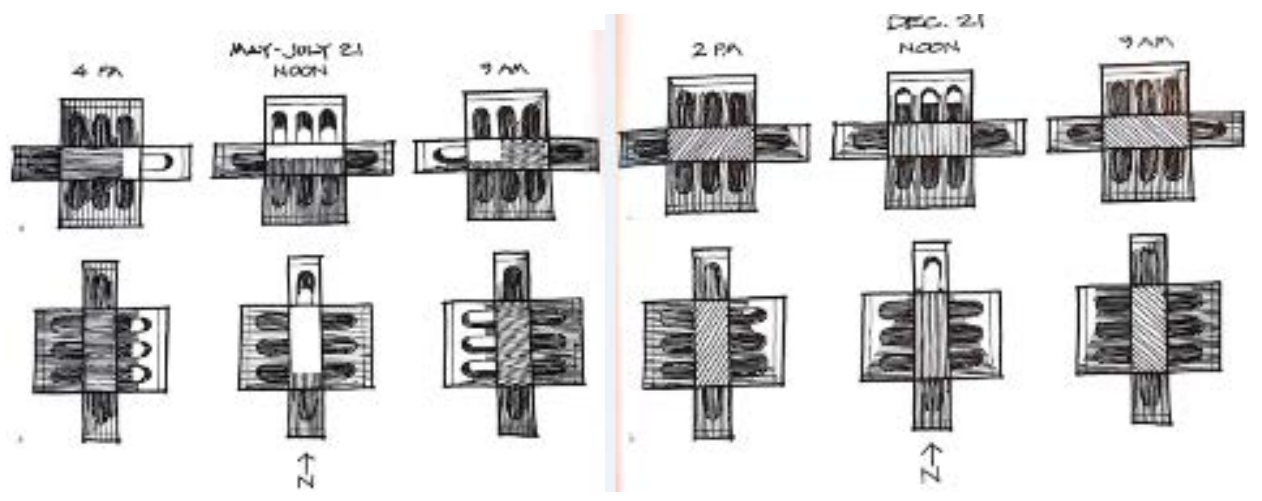

Figure 2: A sketch to show the amount of shade in the courtyard during the year at different times of the day [6].

in January and February are between 10 and $14^{\circ} \mathrm{C}\left(50.0\right.$ and $\left.57.2^{\circ} \mathrm{F}\right)$ [4]. In hot arid zones, use observe narrow streets in urban areas to shade them from the sun, and low rise buildings with an inner courtyard.

Regarding climate, there were three main design factors to consider, insolation, wind and humidity, where most of the studies in the hot arid zones vernacular architecture proved that correct orientation required the designer to study the movement of the sun in summer and winter and in relation to plans and sectional arrangements. It was important to ensure that sunshine was beneficial without the harmful effects of excessive temperatures and glare [5].

Environmentally, a courtyard is a thermal regulator, a small space in the middle of the house surrounded by rooms with different functions connecting them together providing shade and cool because of the surrounding high walls. The cool night air fills the courtyard and the surrounding rooms from the late afternoon time until the sun rises directly in the courtyard where the structure acts like a chimney.

The orientation of courtyards used to be designed to be parallel to the street outside. In most cases the shape of the courtyard is rectangular, that determines the amount of shade provided through the year to the courtyard as well the amount of light provided to the rooms attached to the courtyard, as shown in Fig. 2, a typical proportion for the rooms that face the courtyard ideally are wider along the courtyard than they are deep, to guarantee that the daylight from the courtyard can fill the room more evenly [6].

\subsection{Courtyard social cultural aspects}

The harsh environment in the Arab world affected the houses' design, but other social aspects, such as privacy, were also the main reasons leading to the use of the courtyard in the Arab houses bringing spiritual, functional and climate benefits to the design. With great influence of the Islamic religion, the importance of the courtyard increased as it gives privacy to the family, where the courtyards were used to separate the public domain from the private domain [6].

The courtyards affect the zoning of the house and the organization of spaces with its functions, beginning with the first transition from heat, noise and glare from the street to the cool dark quiet covered entrance to the courtyard. The second transition is the passage through the cool shaded courtyard with some day light, while the last transition is the entrance 
to the private rooms of the house. Islamic religion affected the house zoning distribution beyond the family members and the space functions, and the courtyard played a principal role in this distribution. Table 1 shows each space function and who of the family members are allowed to occupy this space.

\section{COURTYARDS IN SHARJAH VERNACULAR ARCHITECTURE}

Sharjah vernacular architecture corresponded extremely effectively to environmental conditions and social values. The design of residential houses depended on privacy principles as the private spaces opened to an internal open courtyard to provide privacy and isolation.

External elevations were massive and almost solid to protect the inner environment from the harsh climate outside, some small opening appeared in the first floor in repetitive sequences. The urban design is compact and all houses are beside one another, opening onto narrow shaded streets, that provide climate protection [7].

Table 1: A diagram showing the typical grouping of family members for each task. (Source: Friedrich, 2003.)

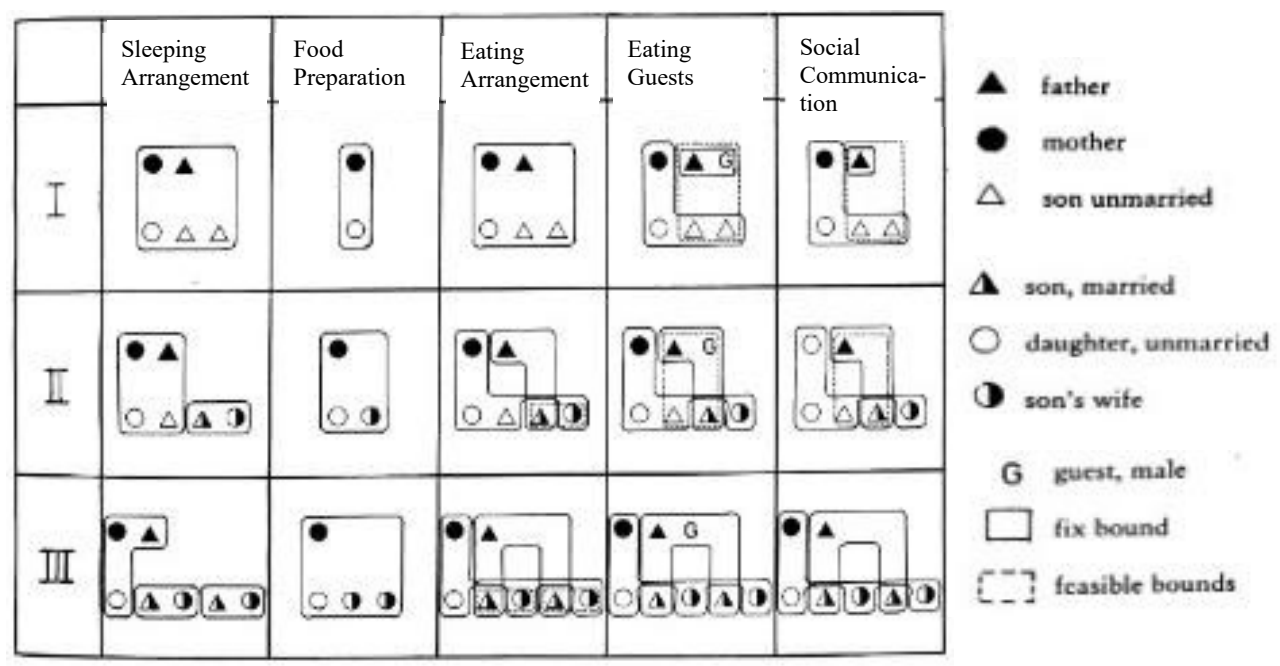

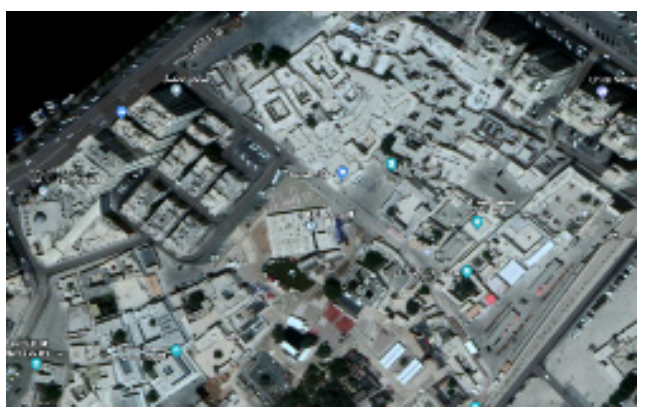

(a)

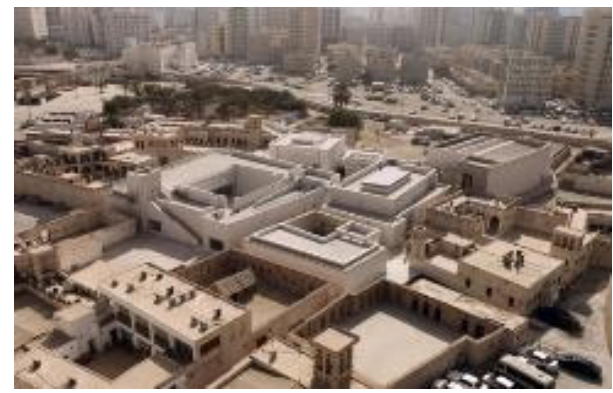

(b)

Figure 3: The layout for old Sharjah heritage area, UAE. (a) Top view; (b) Perspective view of some old houses with inner courtyard. (Source: Authors, 2017.) 


\subsection{Sharjah museums}

The Emirate of Sharjah is a pioneer in the creation of museum infrastructure in the Gulf States [8]. Sharjah Heritage area is a clear example of vernacular architecture in Sharjah, that consists of two tiny neighborhoods, Al Sheyoukh and Al Maraija. There are a number of old traditional Emirati houses that were converted into museums under the umbrella of the Sharjah Heritage Museum; they are linked to the traditional Souq there [9].

What characterizes the heritage area of Sharjah is the traditional activities that express the community's cultural needs and extend the communication roots to introduce historical backgrounds to the new generations, in other words it extends the social sustainability within the Sharjah community. In addition, introducing international events and exhibitions, such as the Sharjah Biennial gives a strong indication of the importance of the community-based hub of the Emirati social life that aims to increase awareness of UAE nationals with their heritage and culture.

The concept of the preservation of old houses in Sharjah to change their function into museums adds value to Sharjah vernacular architecture, as it's noted that these museums become a culture hub internationally, as when they host international art festivals, like Sharjah Biennale, that last for many years. The research covered the urban design for the Sharjah heritage area, and recorded the main museums that were old residential houses before with courtyards, that changed their functions to be social community activities' focal points.

\subsection{Sharjah museums courtyards social activities}

One of the most unique old houses in Sharjah is Bait Al Naboudah (House of Naboudah). This house originally belonged to the late Obaid bin Eissa Bin Ali Al Shamsi, nicknamed Al Naboodah. He was a prominent pearl merchant who held commercial ties with India, Africa and France. Al Naboodah lived in this house, which was built in around 1845, with his three wives and children. The construction of the house went through several phases as his family grew [10].

The house has two stories, and was built around a large courtyard, and the walls made of light coral construction material. Bait Al Naboodah is considered a traditional local prototype house that respected design elements and cultural values, as the function distributed to follow the local social life where we find the Male Majlis beside the entrance in the ground floor near to the kitchen and the guest rooms, the Liwan that separate the public domain from the
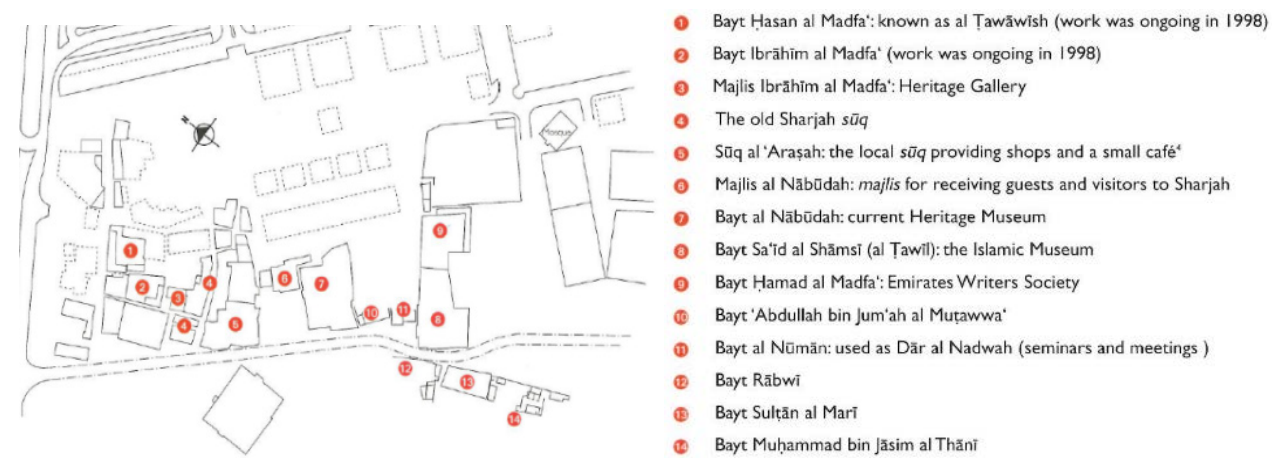

Figure 4: The layout for Sharjah heritage area museums, UAE. (Source: Friedrich, 2003.) 
open courtyard where the private domain starts, and all private family rooms in the first floor [7].

The main function of the traditional building envelope is to protect the building from the extremely hot climate outside. The materials selected are from the area itself. Brick, stone, palm trunks, and wood, and all of these local materials are recyclable and energy efficient. They act as thermal insulation by being used to build thick walls [11].

Most of the rooms are used as display rooms for UAE local's social life collections, and the unique element is the courtyard house where the Sharjah Museums Authority hosts many cultural tourist events and community celebrations and gatherings [10].

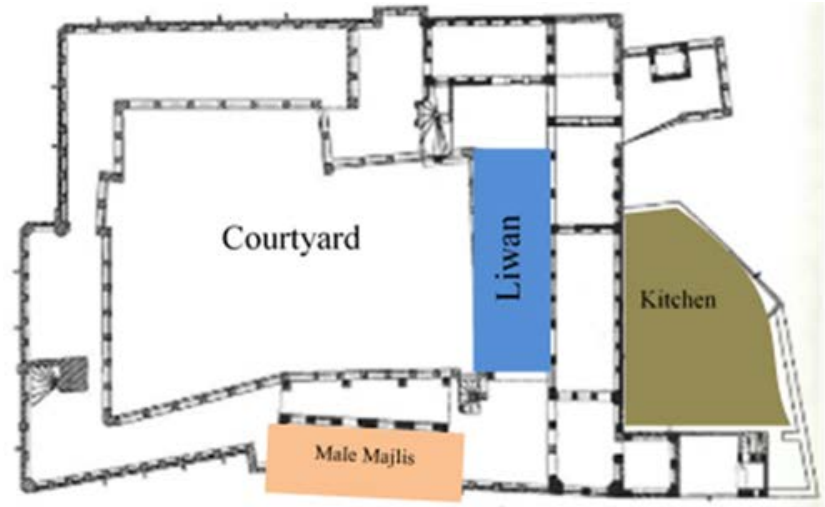

(a)

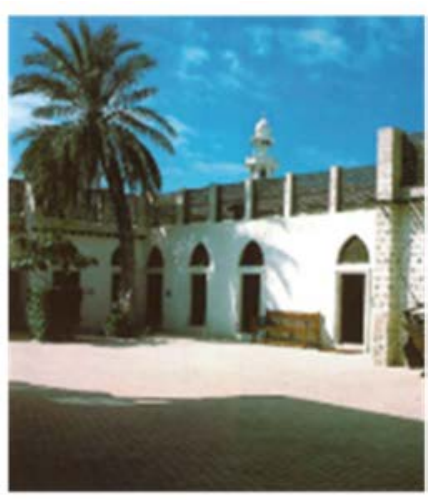

(b)

Figure 5: Bait Al Naboudah in Sharjah, UAE. (a) Plan drawing; and (b) Internal view of the inner courtyard. (Source: Friedrich, 2003.)

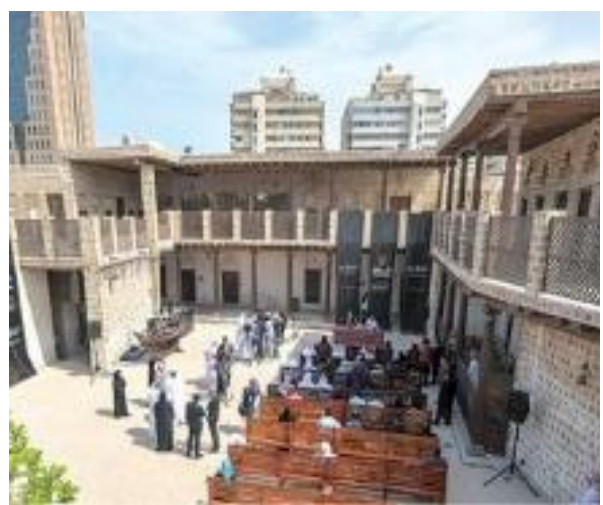

(a)

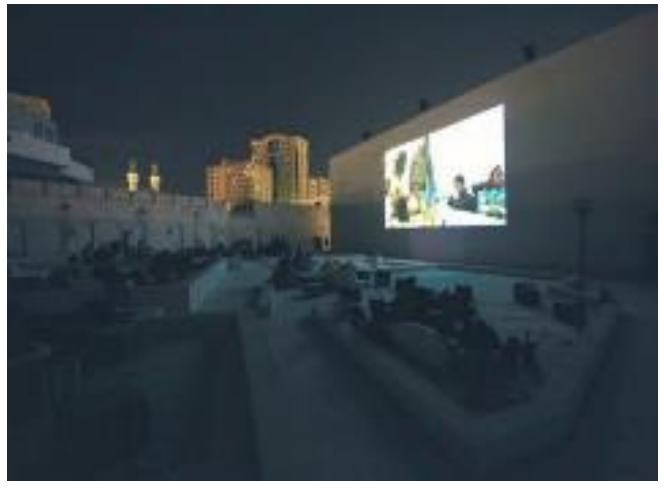

(b)

Figure 6: Bait Al Naboudah's courtyard house in Sharjah, UAE. (a) Day activity in the courtyard; and (b) Night activity for the community in the courtyard. (Source: Authors, 2017.) 


\subsection{Sharjah museums: the model}

During the month of August, 2017, the author interviewed 16 people in pilot interviews. The people interviewed were UAE locals aged from 18 to 40 years old, they came from different backgrounds and lived in different Emirates. The author also interviewed two expatriates who had been living in the United Arab Emirates for the past 10 years.

All of the visitors agreed that they were impressed to visit genuine traditional houses that had been restored as museums. The issues that gave the visitors two different experiences were the history of the vernacular architecture of UAE and the valuable exhibits. The second point in the interviews was the courtyard as a unique thermal system that still works efficiently. They felt the immediate change in temperature once they entered the courtyard.

The model of Sharjah museums highlighted the importance to realize the value of traditional architecture in the UAE with regard to sustainability in vernacular architecture. Restoration, preservation and rehabilitation are significant for old houses in Sharjah to be viable museums that might change the concept that ties traditional architecture in Arab countries with poverty, instead of the superior vision for the implemented western modern architecture.

\section{VERNACULAR ARCHITECTURE INFLUENCE IN SUSTAINABILITY}

Sustainability has a multifaceted nature that cannot be adequately defined nor understood through the tools available in any single discipline. Rather it must be considered from several disciplinary perspectives. The research adopted the Burtland definition of sustainability, where it was clearly defined by the World Commission on Environment and Development in the Brundland report, as: "The development that meets the needs of the present generation without compromising the ability of future generations to meet their own needs" [12].

For many years, the concept of sustainability was limited to the environmental aspect as standalone pillar, but later on, most of the researchers agreed on the three-dimensional model of sustainability with its three pillars, environmental, economic and social. The research argues that these pillars' importance ratios vary from one community to another, as in some communities that have old traditions, social/cultural customs as in Arab communities, the social pillar has more influence. These differences need to be considered in attempts to reach sustainability.

Surveying the three pillars of sustainability in vernacular architecture in Sharjah, it was clear that the environmental pillar was important in order (as stated above) to protect from the harsh climate using the passive energy strategies by the use of natural and renewal resources: using the courtyard houses in residential old houses that utilize natural resources, sun and wind access, for example, as components of healthy comfortable spaces for the inhabitants. Also considering the basic principles of society values in the Emirates' communities, it is necessary to respect the social pillar of sustainability, achieved by traditional houses in Sharjah, as mentioned before in Bait Al Naboudah, in the example that highlighs the social role for the courtyard.

The experience of changing the function of traditional houses in Sharjah into public museums enriches the community's culture with vernacular architecture and people's identity, traditions and heritage as well, as applied in 19 museums in Sharjah that were old residential houses. 


\subsection{Social sustainability in vernacular architecture}

The principles of social sustainability are designed to meet the goals of socially sustainable communities and to this end, are aspirational and visionary statements that describe what makes a community healthy and liveable, both now and in the future [13], where the principles of sustainability are tied to each community and varied in the application.

\subsubsection{Equity}

The community provides equitable opportunities and outcomes for all its members, particularly the poorest and most vulnerable members of the community. While equity is listed as a separate principle, it is such a fundamental component that it can't really be separated from the other principles. The concept of vernacular architecture is to fulfill the community's social and cultural needs that guarantee equity to all inhabitants, and this was clearly illustrated in the design of Sharjah's old houses, where we find clear zoning distribution based on space function and segregation principles, where we can find male zones (Majlis) near the entrance as a public domain providing privacy to female members of the family in the house, as well the design to isolate the servants in the kitchen area near the guests' rooms. All of these considerations increase local family social cohesion [14].

\subsubsection{Diversity}

The community promotes and encourages diversity. The vernacular architecture provided various types of residential houses to fulfill each community's social needs, even in the same country, in local communities the house designs varied from one emirate to another [12], but the courtyard was the main element in design of all types in different emirates.

\subsubsection{Interconnectedness}

The community provides processes, systems and structures that promote connectedness within and outside the community at the formal, informal and institutional level; that is what

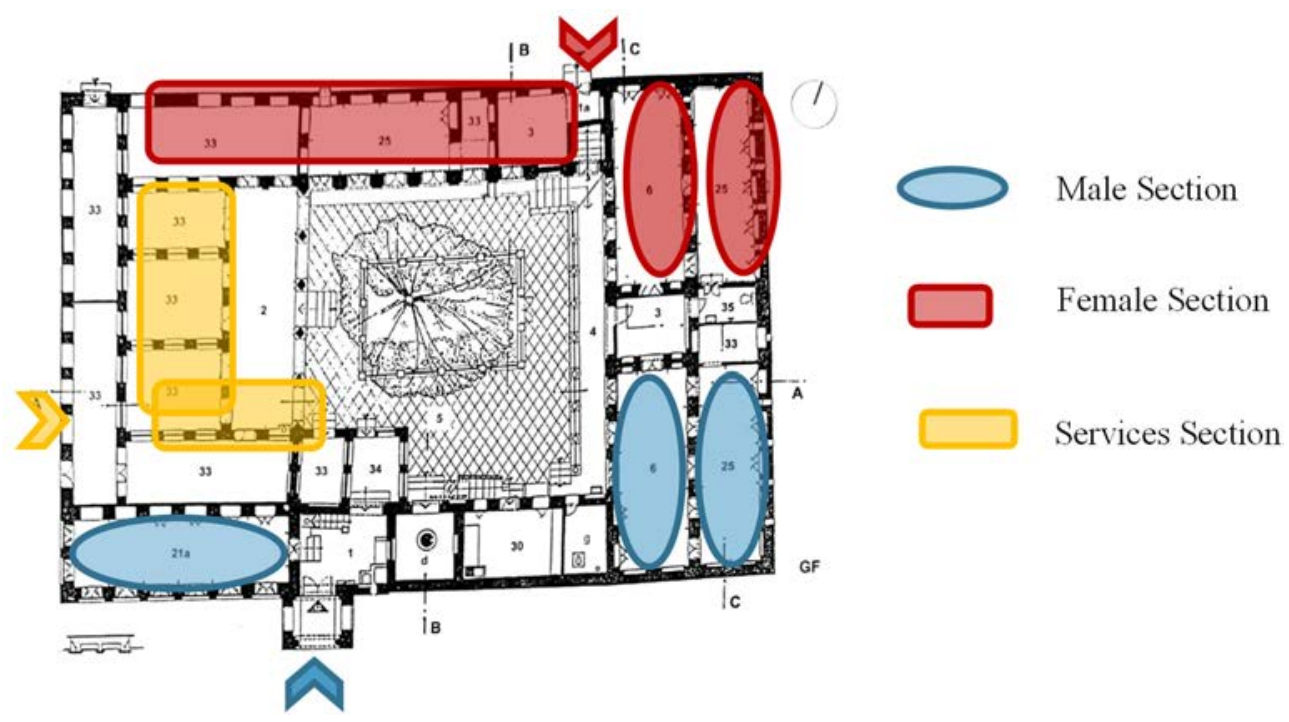

Figure 7: A traditional prototype house showing the different zones with entrances for family members and guests [14]. 


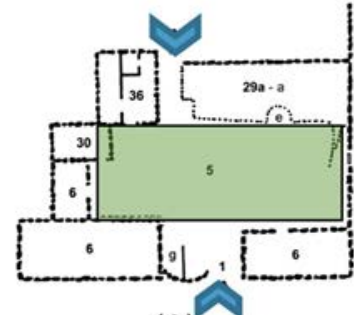

(a)

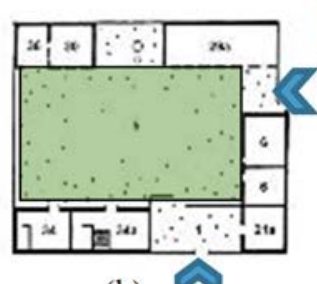

(b)

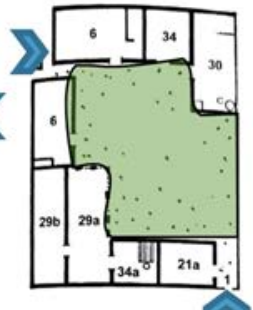

(c)

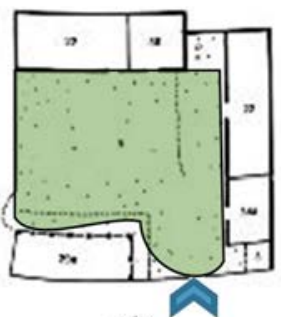

(d)

Figure 8: Various types of traditional houses in UAE. (a) Wadi Al Sham courtyard house; (b) Al Shamel house with entrance leads to male Majlis; (c) Rams house with two opposite entrances; and (d) Ras Al Khaima house with courtyard screen division [6].

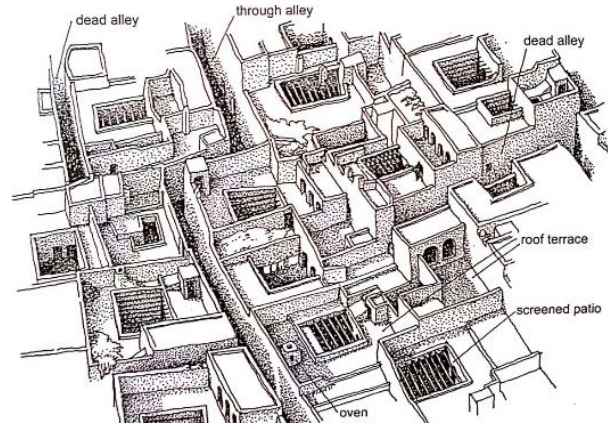

(a)

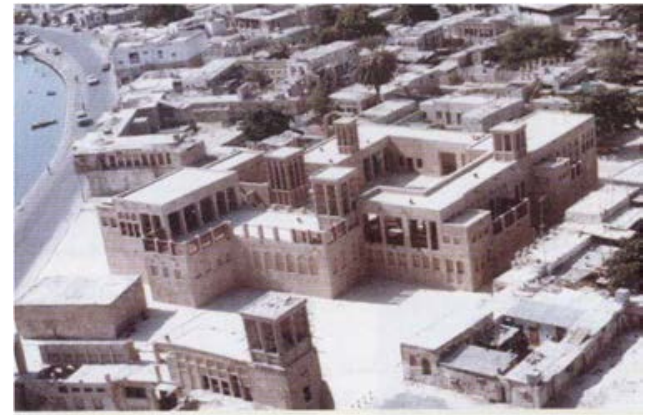

(b)

Figure 9: Old traditional houses compact urban planning of UAE. (a) Sketch of old houses planning; and (b) Old Dubai urban design. (Source: Friedrich, 2003.)

vernacular architecture aims to do. As shown in Fig. 6, the distribution zones in the traditional house plan insure the family ties and the right of each family member to have privacy and to welcome their own guests without interruption to the rest of family members. These are some of the social processes that promote connectedness.

\subsubsection{Quality of life}

The community ensures that basic needs are met and fosters a good quality of life for all members at the individual, group and community level. That's clear on both levels of vernacular architecture, houses and urban planning for neighborhoods in UAE, where the design of local house ensures fulfilling all family members social needs that enrich the sense of belonging and safety, as well the compact design for the houses that create shadow streets which, in turn, enrich the community relationships and the relationship with the surrounding nature.

In the 21 st century, architects are expected to be more creative and well aware with the impact of their designs to the environment and nature as well. In this respect, we can get guidance from traditional vernacular architecture and learn lessons for creating designs that 
are responsive to climate conditions, to the social aspects that fulfil the community requirements related to social culture definitions and values, and to economic aspects that will affect building materials selection which is made from the local environment thus responding to the climate and surrounding environmental aspects.

\subsubsection{Democracy and governance}

The community provides democratic processes and open and accountable governance structures. As mentioned before, vernacular architecture give a clear example in fulfilling the community social needs that gives the community members the sense of belonging leading to transparent social systems enriching the democracy as a life style for such socially sustainable communities.

\section{REFERENCES}

[1] Kennedy, J. \& Joseph, F., Building without Borders, New society Publishers: Canada, 2004.

[2] Bukhash, Rashad, Managing Restoration Projects in Dubai-United Arab Emirates, M. Phil. thesis submitted to the Faculty of Art, University of Manchester, UK. P. 35, 2001.

[3] Fathy, H., Architecture for the poor, An experiment in rural Egypt, The University of Chicago Press: London, p. 65, 1992.

[4] Geography of the United Arab Emirates, Wikipedia Encyclopedia, Online. https://en.wikipedia.org/wiki/Geography_of_the_United_Arab_Emirates\#Climate. Accessed on: 10 Aug. 2018.

[5] Edwards, B., Shalaby, M., Hakim, M. \& Land, P., Courtyard Housing, Taylor and Francis, pp. 156, 2006.

[6] Reynolds, J.S., Courtyards: Aesthetic, Social and Thermal Delight, John Wiley and Sons, Inc.: Hoboken, pp. 192, 2001.

[7] Ragette, F., Traditional Domestic Architecture of the Arab Region, American University of Sharjah: Sharjah, p. 83, 2003.

[8] Bouchenaki, M., The extraordinary development of museums in the gulf states. Museum International, 63(3-4), pp. 93-103, 2011. DOI: 10.1111/muse.12010.

[9] Burhaima, A., Programmes designed for visitors to the museums of sharjah. Museum International, 63(3-4), pp. 35-40, 2011. DOI: 10.1111/muse.12004.

[10] Sharjah Museums, Bait AL Naboudah, Sharjah Museums Authority. Online. www.sharjahmuseums.ae/Our-Museums/Bait-Al-Nabooda.aspx. Accessed on: 23 May 2018.

[11] Kim, J.J. \& Rigdon, B., Sustainable Architecture Module: Introduction to Sustainable Design. National Pollution Prevention Centre for Higher Education, The University of Michigan: Michigan, pp. 8-15, 1998.

[12] Lafferty, W.M. \& Langhelle, O., Towards Sustainable Development: On the Goals of Development and the Conditions of Sustainability, Palgrave Macmillan: Basingstoke, Jul. 1999.

[13] Barron, L. \& Gauntlett, E., Housing and sustainable communities' indicators project, Lotteries Commission of Western Australia, p. 10, 2002.

[14] Al-Rostomani, A.H., Dubai and Its Architectural Heritage, Al-Safeer Publishing and Advertising Establishment: Dubai, p. 166, 1991. 